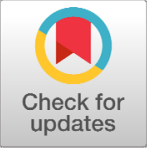

Received: Nov 28, 2021

Revised: Dec 15, 2021

Accepted: Dec 15, 2021

*Corresponding author

Jung Min Heo

Department of Animal Science and

Biotechnology, Chungnam National

University, Daejeon 34134, Korea

Tel: +82-42-821-5777

E-mail: jmheo@cnu.ac.kr

Copyright () 2021 Korean Society of Animal Science and Technology.

This is an Open Access article distributed under the terms of the Creative Commons Attribution Non-Commercial License (http://creati vecommons.org/licenses/by-nc/4.0) which permits unrestricted non-commercial use, distribution, and reproduction in any medium, provided the original work is properly cited.

ORCID

Myunghwan $\mathrm{Yu}$ https://orcid.org/0000-0003-4479-4677 Jung Min Heo

https://orcid.org/0000-0002-3693-1320

\section{A comprehensive overview of coccidiosis in chicken}

\author{
Myunghwan Yu and Jung Min Heo* \\ Department of Animal Science and Biotechnology, Chungnam National University, Daejeon \\ 34134, Korea
}

\begin{abstract}
Coccidiosis is the main parasitic disease resulting from the intracellular protozoan that targets each different part of the intestinal tract leading to destroy in poultry. For this reason, coccidiosis induces an enormous economic loss in the poultry industry. Eimeria life cycle is complicated and comprised of exogenous and endogenous stages inducing an inflammatory response which results in enteric damage associated with diarrheal hemorrhage, disorder digestion of feed and nutrient absorption, dehydration, blood loss, mortality. Hence, it is very important to understand the information of Eimeria parasites for elimination and treatment. This disease has been controlled by various anticoccidial drugs and vaccines as the most common management practices. However, not only the occurrence of drug resistance due to anticoccidial drugs but lack of a guarantee of safety with vaccine use, has led to the development of alternative strategies to control coccidiosis. For these reasons, phytogenic compounds are emerging for the control and prevention of poultry coccidiosis to alternate previous methods. The main aim of this review is to provide an overview of coccidiosis including etiology, morphology, life cycle, pathogenicity, clinical sign, diagnosis, control and prevention.
\end{abstract}

Keywords: Coccidiosis, Eimeria, Broiler, Etiology, Life cycle, Prevention

\section{INTRODUCTION}

Chickens are major species globally adapted to a range of climatic conditions in which humans live and play an important role in supplying animal-derived proteins to improve human nutrition [1].

Coccidiosis is recognized as a pandemic disease of broilers caused by the intracellular protozoan parasites of the genus Eimeria. Although coccidiosis is known for many years, it is still considered as the major economical parasitic condition affecting poultry industries [2,3]. The major part of these economical damages is due to losses in performance including mortality, weight loss and reduced nutrition digestibility resulting in malabsorption caused by gut damage. The minor part of these economical damages is due to the costs of therapy and prophylaxis [4-6].

For controlling coccidiosis in broilers, various preventive medications have been approved for use globally and approached, but resistance is increasingly important as no new anticoccidial compounds are known to be under development [2]. Therefore, the purpose is to provide available information on coccidiosis in broilers and to highlight etiology, life cycle and preventive measures. 
Competing interests

No potential conflict of interest

relevant to this article was reported.

Funding sources

Not applicable.

Acknowledgements

Not applicable.

Availability of data and material

Upon reasonable request, the

datasets of this study can be

available from the corresponding

author.

Authors' contributions

Conceptualization: Yu M, Heo JM

Validation: Heo JM.

Investigation: $\mathrm{Yu} \mathrm{M}$, Heo JM.

Writing - original draft: $\mathrm{Yu} M$.

Writing - review \& editing: $Y u$ M, Heo

JM.

Ethics approval and consent to participate

This article does not require IRB/

IACUC approval because there are no human and animal participants.

\section{ETIOLOGY}

Coccidiosis in broilers is caused by the intracellular protozoan parasite in the genus Eimeria family Eimeridae order Eucoccidiorida and phylum Apicomplexa. Seven species of Eimeria (E. acervulina, E. brunetti, E. maxima, E. mitis, E. necatrix, E. praecox, and E. tenella) are recognized to infect chickens [7]. All the Eimeria spp. are very host-specific and sites of development are certain sites of the intestinal tract in broilers with different pathogenicity [8] (Table 1). Concurrent infection with at least six species is prevalent in a single flock causing marked, independent, recognizable diseases leading to the subclinical intestinal infection to sub-acute mortality [9].

\section{MORPHOLOGY}

Oocyst of Eimeria spp. is a robust wall resistant to both mechanical, chemical and proteolytic degradation. Its wall has been associated with a bilayer structure composed of lipid and protein. The protein layer provides great stability against extreme cold and heat while the lipid layer supplies a cushion against chemical damage $[10,11]$. There are two types of oocysts depending on the infectious ability. Sporulated oocysts are infectious while unsporulated oocysts are noninfectious [12]. The sporulated oocyst can survive up to 602 days in the external environment of its host whereas unsporulated oocysts can survive for seven months in the host caecum [11]. The oocyst is unsporulated and noninfectious in the majority of cases whereas unsporulated oocysts can be converted into sporulated oocysts with appropriate temperatures and humidity. This process is known as sporulation [8] and sporulated Eimeria oocyst is composed of four sporocysts and each with two sporozoites and the lsospora has two sporocysts, each with four sporozoites [13]. Oocysts of distinct species show contrasts of size (area, diameter), contour (elliptic, ovoid, circular), thickness, internal structure and color of the oocyst wall among other morphological variations [14].

Table 1. Main characteristics of Eimeria species in the host

\begin{tabular}{lcc}
\hline Eimeria species & Predilection site & Pathogenicity \\
\hline E. praecox & Duodenum, jejunum & Least pathogenic \\
E. acervulina & Duodenum, ileum & Less pathogenic \\
E. mitis & lleum & Less pathogenic \\
E. maxima & Jejunum, ileum & Moderately-highly pathogenic \\
E. brunetti & Caeca and rectum & Highly pathogenic \\
E. tenella & Caeca & Highly pathogenic \\
E. necatrix & Jejunum, ileum, caeca & Highly pathogenic
\end{tabular}

Adapted from [8] with CC-BY. 


\section{LIFE CYCLE}

Eimeria species follow a complex life cycle, consisting of two developmental stages namely the exogenous phase (sporogony; occurs in the outer environment) and the endogenous phase (schizogony/merogony and gametogony) [5,15]. The life cycle of all Eimeria species entails two or more generations of an asexual development (schizogony), then merogony and followed by a sexual phase known as gametogony which contributes to the formation of the oocyst [1]. Under suitable conditions of temperature and moisture unsporulated oocysts develops within 24-48 hours to form a sporulated oocyst. The sporulated oocyst possesses four sporocysts, each containing two sporozoites (the infective agent). These oocysts can remain viable in the litter for a prolonged period (months to years) under conditions upon ingestion by a suitable host. Birds intake the sporulated oocyst by pecking in the litter for bedding or on the ground [16,17]. This process is the action of mechanical and chemical (i.e., trypsin, bile salt, carbon dioxide) factors that leads to the release of sporocysts and then sporozoites within the intestinal lumen of birds $[1,16]$.

Excystation contributes to the opening of the anterior cap of sporocysts for releasing sporozoites. Interactions between the apical complex and the plasma membrane of epithelial cells permit sporozoites to penetrate the host cell [18]. The released sporozoites penetrate directly into host intestinal epithelial cells in a specific site of the intestine determined by the species of Eimeria. After the invasion, sporozoites convert into a growing stage named trophozoites, which get enlarged and divide asexually to generate a large number of merozoites (known as merogony). Merozoites are separated from the original infected host epithelial cell to infect new cells in both the small and large intestine, developing on the second cycle of merogony $[16,19,20]$. In the last merogonic cycle, the resulting merozoites invade adjacent epithelial cells undergoing the sexual phase of the life cycle known as gametogenesis. During gametogenesis, these merozoites develop into either microgametes or macrogametes. Microgametes give rise to the release of numerous minute biflagellate microgametes, that exit, seek, and fertilize the macrogamete then form a zygote. This stage is the immature oocyst $[5,15,21]$.

The diploid zygote produced during fertilization forms the oocyst wall capacity strong resistance and invades the intestinal lumen. Ultimately, Sporulation arises within infective sporozoites that grow and pollute the environment to begin a new cycle [1]. The life cycle of Eimeria generally takes $4-6$ days $[16,22]$.

\section{PATHOGENICITY}

Pathogenicity in Eimeria deteriorates with boosting the number of sporulated oocysts ingested by the host [23]. Infection of Eimeria impairs the intestinal epithelial cells and tissues, destabilizing the gut of chickens [24]. As a result, coccidiosis leads to disorder digestion of feed and nutrient absorption, dehydration, blood loss and loss of skin pigmentation [25]. Moreover, Eimeria spp. change the overall morphology of the intestinal microbiota in the gut, truncating 
intestinal villi which result in a decreased ability for the digestion and absorption of nutrients [26].

\section{CLINICAL SIGN}

Coccidiosis of broilers affects two forms as sub-clinical and clinical [1]. In sub-clinical coccidiosis, the symptom demonstrates poor weight gain and deteriorated feed efficiency, reduced growth rate and causes an enormous proportion of the economic loss [27]. Clinical signs of coccidiosis are on account of the destruction of the intestinal epithelium and underlying connective tissue of the mucosa. It may go along with hemorrhage into the lumen of the intestine as symptoms advance. Accordingly, the clinical form of coccidiosis appears in weight loss, reduced feed intake, paleness, ruffled feathers, depression, pale color comb, wattles, huddling, closed eyes, diarrhea with bloody feces, dehydration and increased number of mortality may accompany $[1,28]$.

\section{DIAGNOSIS}

\section{Lesion scoring}

Lesion scoring is the method to interpret poultry coccidiosis by observing each of the intestinal tracts for macroscopically visible lesions which are following a scoring system from 0 to 4 (i.e., $0=$ healthy or no sign of infection, 1 = mild lesions, 2 = moderate lesions, 3 = severe lesions, 4 = extremely severe lesions) caused by Eimeria [29]. This method is work-intensive by investigating post-mortem, occasionally subjective and only dependable when performed by veterinarians or highly trained individuals [30].

\section{Detection of oocyst in feces}

Eimeria oocysts can be acquired easily from the feces of infected birds hence using oocyst character is a non-invasive method to determine the causative species in chickens.

\section{Qualitative techniques for fecal examinations}

The most extensively used method for the concentration of parasite oocysts is flotation. A solution with a higher specific gravity (i.e., saturated $\mathrm{NaCl}+$ glucose) is used to float the relatively low specific gravity coccidial oocysts to the surface and remained other debris in feces at the bottom of the solution [31].

\section{Quantitative techniques for fecal examinations}

This method is carried out to determine the number of oocysts per gram of feces (OPG count) together with the percentage of sporulation and oocyst dimensions. Typically, the McMaster chamber method is used for counting Eimeria oocysts in the fecal solution and for establishing the individual oocysts shedding pattern of an infected bird [21]. The floatation method of oocysts is identical to the quantitative technique and uses the McMaster sliced to facilitate easy counting 
through the light microscope [32]. Nevertheless, expertise is required to identify the different species based on the morphology of oocysts [2].

\section{Molecular biological diagnosis}

Although traditional methods such as lesion scoring and oocyst detection in feces are still being used, molecular biological methods are applicable in most research since the above mentioned traditional methods are time-intensive and in the case of detection of oocyst, it is hard to distinguish what kind of oocysts are there [11].

Previous techniques distinguishing of different species were based on the isoenzyme patterns of oocysts and rRNA and rDNA proves [33,34]. Polymerase chain reaction (PCR) is a rapid, accurate and highly sensitive molecular diagnostic technique to identify the Eimeria spp. in chickens by inspecting their variations of genomic DNA [35]. This method amplifies the chicken coccidian species-specific DNA sequence for the detection and discrimination to hundreds of millions for a few hours and the new copies can be divided by electrophoresis to visualize it under UV light by a fluorescent dye [23,36].

\section{TREATMENT, CONTROL AND PREVENTION}

\section{Anticoccidial drugs}

Chemoprophylaxis for the treatment and prevention of coccidiosis has been accomplished by the inclusion of a range of anticoccidial drugs in the feed or drinking water to the chickens $[8,37]$. Anticoccidial drugs can be classified into three categories as follows: i) Synthetic compounds, ii) Ionophores/polyether antibiotics, iii) Mixed products of the synthetic compounds and ionophores [16,38]. Unfortunately, most of the anticoccidial drugs became ineffective due to drug resistance [39].

\section{Synthetic compounds}

Synthetic compounds are manufactured by chemical synthesis and are often known as 'chemicals' [38]. Synthetic drugs work by preventing different biochemical pathways of the developing parasite metabolism [40]. Sulfonamides, nicarbazin, clopidol, quinolones, amprolium, halofuginone are chemical components' examples of commonly used synthetic drugs [38,41].

\section{lonophores/polyether antibiotics}

Ionophores/polyether antibiotics are manufactured by the fermentation of Streptomyces spp. or Actinomadura spp. and arrest the ion (i.e. sodium, potassium) transport channels and hinder the osmotic balance of the coccidian species [38,42]. The groups of ionophores can be classified into three categories as follow: i) Monovalent ionophores (monensin, narasin, salinomycin), ii) Monovalent glycosidic ionophores (maduramicin, semduramycin), iii) Divalent ionophores (lasalocid) [37]. 


\section{Vaccination}

The intensive use of anticoccidial drugs which resulted in the development of resistance, chemical residues and environmental pollution of poultry products promoted research on alternative control methods such as early application of vaccines or the development of new drugs [43]. There are two types of available live vaccines for the immunization of chickens as follows: i) virulent vaccines, ii) attenuated vaccines [44].

\section{Virulent vaccines}

Virulent (Unattenuated) vaccines are comprised of Eimeria species originating from laboratory or field strains, which have not been modified in any way to change their pathogenicity [38]. Although these vaccines induce a healthy immune activity in the poultry, the exposure to the oocytes of Eimeria must arise again through the litter to maintain the immune status to the same level as birds saved previous induced immune activity [45]. Furthermore, it is necessary to inoculate the recommended dosage of virulent vaccines to avoid clinical coccidiosis from the birds [38].

\section{Attenuated vaccines}

Attenuated vaccines are produced downgrading the virulence of Eimeria species artificially, making minimum damage to the intestinal epithelium after one passage through the gut [3]. Notwithstanding these vaccines are safe, the price of their production is high because of the decreasing fecundity of precocious parasites [44], and 2-3 cycles of Eimeria are requisite for maximum acquired immunity [46].

\section{Phytogenic compounds}

Phytogenic compounds are a wide range of plant-derived products that find use as prophylactic agents in enhancing performance, productivity as well as alleviating harmful effects of coccidiosis $[47,48]$. Furthermore, these compounds include antioxidant, antimicrobial, antiparasitic and antiviral properties [49]. Currently, various studies related to phytochemicals are being conducted to replace the traditional methods (i.e., vaccination, use of anticoccidial drugs) for preventing poultry coccidiosis on account of safety, efficient price, drug resistance and drug residues [50-52].

\section{Oregano extracts}

Oregano extracts as phytogenic compounds are known to have positive effects on growth performance as well as the efficacy of cocci elimination of coccidiosis-infected broilers [53,54]. Among them, phenols such as carvacrol and thymol have been analyzed as they exhibit plentiful biological properties, including antioxidant, antifungal, antibacterial, and antiprotozoal effects against Eimeria spp. [52,55,56]. The high lipid solubility and hydrophobicity of carvacrol and thymol led to interaction with the phospholipid bilayer in the Eimeria species cell membrane, resulting in a change in membrane permeability for cations such as $\mathrm{H}^{+}$and $\mathrm{K}^{+}$. Consequently, 
the collapse of the parasitic cells occurs through energy losses (i.e., ATPase inhibition) and ion leakage (particularly calcium), resulting in water imbalance [52,57].

\section{3,4,5-Trihydroxybenzoic acid (THB)}

3,4,5-Trihydroxybenzoic acid, also known as gallic acid, is found in several vegetables and fruits [58]. Gallic acid is made up of a low molecular weight tri-phenolic compound. It possesses anti-inflammatory and anti-oxidative activities as well as several evident pharmacological effects including anti-tumor, anti-bacterial, anti-diabetes, anti-obesity, anti-microbial and anti-myocardial ischemia [59].

\section{CONCLUSION}

Coccidiosis is a major enteric parasitic disease in the poultry industry and is caused by seven Eimeria parasite species developing in a particular chick's digestive tract. These species induce symptoms from subclinical enteric infection to subacute mortality. For these reasons, coccidiosis is still mightily important to prevent economic loss worldwide. Although diverse control measures have been accomplished against the disease, prophylactic use of anticoccidial drugs was an extensively used control approach which makes a problem of drug resistance recently. Hence, phytogenic compounds are emerging for the control and prevention of poultry coccidiosis instead of previous methods. Therefore, there need for various researches related to phytogenic compounds affecting coccidiosis in broilers.

\section{REFERENCES}

1. Abebe E, Gugsa G. A review on poultry coccidiosis. Abyss J Sci Technol. 2018;3:1-12. https://doi.org/10.20372/ajst.2018.3.1.76

2. De Gussem M. Coccidiosis in poultry: review on diagnosis, control, prevention and interaction with overall gut health. In: Proceedings of the 16th European Symposium on Poultry Nutrition; 2007; Strasbourg, France.

3. Acharya KP, Acharya N. Alternatives to fight against coccidiosis: a review. Nepalese Vet J. 2017;34:152-67. https://doi.org/10.3126/nvj.v34i0.22918

4. Amerah AM, Ravindran V. Effect of coccidia challenge and natural betaine supplementation on performance, nutrient utilization, and intestinal lesion scores of broiler chickens fed suboptimal level of dietary methionine. Poult Sci. 2015;94:673-80. https://doi.org/10.3382/ps/pev022

5. Muthamilselvan T, Kuo TF, Wu YC, Yang WC. Herbal remedies for coccidiosis control: a review of plants, compounds, and anticoccidial actions. Evid Based Complement Alternat Med. 2016;2016:2657981. https://doi.org/10.1155/2016/2657981

6. Gómez-Osorio LM, Chaparro-Gutiérrez JJ, López-Osorio S. Nutrition and poultry coccidiosis: causes, consequences and current strategies to modulate the disease. In Patra, editor. Advances in poultry nutrition research. London: IntechOpen; 2021. 
7. Shirley MW, Smith AL, Tomley FM. The biology of avian Eimeria with an emphasis on their control by vaccination. Adv Parasitol. 2005;60:285-330. https://doi.org/10.1016/S0065$308 \mathrm{X}(05) 60005-\mathrm{X}$

8. Quiroz-Castañeda RE, Dantán-González E. Control of avian coccidiosis: future and present natural alternatives. BioMed Res Int. 2015;2015:430610. https://doi.org/10.1155/2015/430610

9. El-Shall EA, Abd El-Hack ME, Albaqami NM, Khafaga AF, Taha AE, Swelum AA, et al. Phytochemical control of poultry coccidiosis: a review. Poult Sci. 2022;101:101542. https://doi.org/10.1016/j.psj.2021.101542

10. Mai K, Sharman PA, Walker RA, Katrib M, Souza DD, McConville MJ, et al. Oocyst wall formation and composition in coccidian parasites. Mem Inst Oswaldo Cruz. 2009;104:281-9.

11. Fatoba AJ, Adeleke MA. Diagnosis and control of chicken coccidiosis: a recent update. J Parasit Dis. 2018;42:483-93. https://doi.org/10.1007/s12639-018-1048-1

12. Lal K, Bromley E, Oakes R, Prieto JH, Sanderson SJ, Kurian D, et al. Proteomic comparison of four Eimeria tenella life-cycle stages: unsporulated oocyst, sporulated oocyst, sporozoite and second-generation merozoite. Proteomics. 2009;9:4566-76. https://doi.org/10.1002/pmic.200 900305

13. Belli SI, Smith NC, Ferguson DJP. The coccidian oocyst: a tough nut to crack! Trends Parasitol. 2006;22:416-23. https://doi.org/10.1016/j.pt.2006.07.004

14. Castañón CAB, Fraga JS, Fernandez S, Gruber A, Costa LF. Biological shape characterizati on for automatic image recognition and diagnosis of protozoan parasites of the genus Eimeria. Pattern Recognit. 2007;40:1899-910. https://doi.org/10.1016/j.patcog.2006.12.006

15. López-Osorio S, Chaparro-Gutiérrez JJ, Gómez-Osorio LM. Overview of poultry Eimeria life cycle and host-parasite interactions. Front Vet Sci. 2020;7:384. https://doi.org/10.3389/ fvets. 2020.00384

16. Allen PC, Fetterer RH. Recent advances in biology and immunobiology of Eimeria species and in diagnosis and control of infection with these coccidian parasites of poultry. Clin Microbiol Rev. 2002;15:58-65. https://doi.org/10.1128/CMR.15.1.58-65.2002

17. Fanatico A. Parasite management for natural and organic poultry: coccidiosis. Box Hill, Australia: ATTRA Publications; 2006.

18. Grimwood J, Smith JE. Toxoplasma gondii: the role of parasite surface and secreted proteins in host cell invasion. Int J Parasitol. 1996;26:169-73. https://doi.org/10.1016/0020-7519(95) 00103-4

19. Innes EA, Vermeulen AN. Vaccination as a control strategy against the coccidial parasites Eimeria, Toxoplasma and Neospora. Parasitology. 2006;133:S145-68. https://doi.org/10.1017/S 0031182006001855

20. Blake DP, Worthing K, Jenkins MC. Exploring Eimeria genomes to understand population biology: recent progress and future opportunities. Genes. 2020;11:1103. https://doi.org/10.3390/ genes11091103

21. Conway DP, McKenzie ME. Poultry coccidiosis: diagnostic and testing procedures. 
Hoboken, NJ: John Wiley \& Sons; 2007.

22. McDougald LR. Intestinal protozoa important to poultry. Poult Sci. 1998;77:1156-8. https://doi.org/10.1093/ps/77.8.1156

23. Morris GM, Gasser RB. Biotechnological advances in the diagnosis of avian coccidiosis and the analysis of genetic variation in Eimeria. Biotechnol Adv. 2006;24:590-603. https://doi.org/ 10.1016/j.biotechadv.2006.06.001

24. Madlala T, Okpeku M, Adeleke MA. Understanding the interactions between Eimeria infection and gut microbiota, towards the control of chicken coccidiosis: a review. Parasite. 2021;28:48. https://doi.org/10.1051/parasite/2021047

25. Adamu M, Boonkaewwan C, Gongruttananun N, Vongpakorn M. Hematological, biochemical and histopathological changes caused by coccidiosis in chickens. Agric Nat Resour. 2013;47:238-46.

26. Silversides FG, Remus J. Betaine improves performance of coccidia-challenged birds. World Poult Spec Suppl Coccidiosis. 1999;3:37-8.

27. Taylor MA, Coop RL, Wall RL. Veterinary parasitology. 3rd ed. Oxford, UK: Blackwell Science. 2007.

28. Hafez HM. Poultry coccidiosis: prevention and control approaches. Arch Geflügelk. 2008;72(1):2-7.

29. Johnson J, Reid WM. Anticoccidial drugs: lesion scoring techniques in battery and floor-pen experiments with chickens. Exp Parasitol. 1970;28:30-6. https://doi.org/10.1016/0014-4894 (70)90063-9

30. De Gussem M, Huang S. The control of coccidiosis in poultry. Int Poult Prod. 16:7-12.

31. Olanrewaju CA, Agbor RY. Prevalence of coccidiosis among poultry birds slaughtered at Gwagwalada main market, Abuja, FCT, Nigeria. Int J Eng Sci. 2014;3:41-5.

32. Vadlejch J, Petrtýl M, Zaichenko I, Čadková Z, Jankovská I, Langrová I, et al. Which McMaster egg counting technique is the most reliable? Parasitol Res. 2011;109:1387-94. https://doi.org/10.1007/s00436-011-2385-5

33. Shirley MW. Enzyme variation in Eimeria species of the chicken. Parasitology. 1975;71: 369-76. https://doi.org/10.1017/S0031182000047144

34. Ellis J, Bumstead J. Eimeria species: studies using rRNA and rDNA probes. Parasitology. 1990;101:1-6. https://doi.org/10.1017/S0031182000079671

35. Schnitzler BE, Thebo PL, Mattsson JG, Tomley FM, Shirley MW. Development of a diagnostic PCR assay for the detection and discrimination of four pathogenic. Eimeria species of the chicken. Avian Pathol. 1998;27:490-7. https://doi.org/10.1080/03079459808419373

36. Schnitzler BE, Thebo PL, Tomley FM, Uggla A, Shirley MW. PCR identification of chicken Eimeria: a simplified read-out. Avian Pathol. 1999;28:89-93. https://doi.org/10.1080/030794 59995091

37. Chapman HD. Anticoccidial drugs and their effects upon the development of immunity to Eimeria infections in poultry. Avian Pathol. 1999;28:521-35. https://doi.org/10.1080/030794 59994317 
38. Peek HW, Landman WJM. Coccidiosis in poultry: anticoccidial products, vaccines and other prevention strategies. Vet Q. 2011;31:143-61. https://doi.org/10.1080/01652176.2011.605247

39. Chapman HD. Biochemical, genetic and applied aspects of drug resistance in Eimeria parasites of the fowl. Avian Pathol. 1997;26:221-44. https://doi.org/10.1080/03079459708419208

40. Chapman HD, Jeffers TK, Williams RB. Forty years of monensin for the control of coccidiosis in poultry. Poult Sci. 2010;89:1788-801. https://doi.org/10.3382/ps.2010-00931

41. Chapman HD. A review of the biological activity of the anticoccidial drug nicarbazin and its application for the control of coccidiosis in poultry. Poult Sci Rev. 1994;5:231-43.

42. Khater HF, Ziam H, Abbas A, Abbas RZ, Raza MA, Hussain K, et al. Avian coccidiosis: recent advances in alternative control strategies and vaccine development. Agrobiol Rec. 2020;1:11-25. https://doi.org/10.47278/journal.abr/2020.004

43. Yim D, Kang SS, Kim DW, Kim SH, Lillehoj HS, Min W. Protective effects of Aloe vera-based diets in Eimeria maxima-infected broiler chickens. Exp Parasitol. 2011;127:322-5. https://doi.org/10.1016/j.exppara.2010.08.010

44. Chapman HD, Cherry TE, Danforth HD, Richards G, Shirley MW, Williams RB. Sustainable coccidiosis control in poultry production: the role of live vaccines. Int $\mathrm{J}$ Parasitol. 2002;32:617-29. https://doi.org/10.1016/S0020-7519(01)00362-9

45. Sharman PA, Smith NC, Wallach MG, Katrib M. Chasing the golden egg: vaccination against poultry coccidiosis. Parasite Immunol. 2010;32:590-8. https://doi.org/10.1111/j.1365-3024.20 10.01209.x

46. Blake DP, Pastor-Fernández I, Nolan MJ, Tomley FM. Recombinant anticoccidial vaccines - a cup half full? Infect Genet Evol. 2017;55:358-65. https://doi.org/10.1016/j.meegid.2017. 10.009

47. Alloui MN, Agabou A, Alloui N. Application of herbs and phytogenic feed additives in poultry production-a review. Glob J Anim Sci Res. 2014;2:234-43.

48. Shivaramaiah C, Barta J, Hernandez-Velasco X, Téllez G, Hargis B. Coccidiosis: recent advancements in the immunobiology of Eimeria species, preventive measures, and the importance of vaccination as a control tool against these Apicomplexan parasites. Vet Med Res Rep. 2014;5:23-34. https://doi.org/10.2147/VMRR.S57839

49. Brenes A, Roura E. Essential oils in poultry nutrition: main effects and modes of action. Anim Feed Sci Technol. 2010;158:1-14. https://doi.org/10.1016/j.anifeedsci.2010.03.007

50. Abbas RZ, Colwell DD, Gilleard J. Botanicals: an alternative approach for the control of avian coccidiosis. Worlds Poult Sci J. 2012;68:203-15. https://doi.org/10.1017/S0043933912 000268

51. Giannenas I, Papaneophytou CP, Tsalie E, Pappas I, Triantafillou E, Tontis D, et al. Dietary supplementation of benzoic acid and essential oil compounds affects buffering capacity of the feeds, performance of turkey poults and their antioxidant status, $\mathrm{pH}$ in the digestive tract, intestinal microbiota and morphology. Asian-Australas J Anim Sci. 2014;27: 225-36. https://doi.org/10.5713/ajas.2013.13376

52. Mohiti-Asli M, Ghanaatparast-Rashti M. Dietary oregano essential oil alleviates experimentally 
induced coccidiosis in broilers. Prev Vet Med. 2015;120:195-202.

53. Reisinger N, Steiner T, Nitsch S, Schatzmayr G, Applegate TJ. Effects of a blend of essential oils on broiler performance and intestinal morphology during coccidial vaccine exposure. J Appl Poult Res. 2011;20:272-83. https://doi.org/10.3382/japr.2010-00226

54. Tsinas A, Giannenas I, Voidarou C, Tzora A, Skoufos J. Effects of an oregano based dietary supplement on performance of broiler chickens experimentally infected with Eimeria acervulina and Eimeria maxima. J Poult Sci. 2011;48:194-200. https://doi.org/10.2141/jpsa.010123

55. Giannenas I, Florou-Paneri P, Papazahariadou M, Christaki E, Botsoglou NA, Spais AB. Effect of dietary supplementation with oregano essential oil on performance of broilers after experimental infection with Eimeria tenella. Arch Anim Nutr. 2003;57:99-106. https://doi.org/ 10.1080/0003942031000107299

56. Rúa J, del Valle P, de Arriaga D, Fernández-Álvarez L, García-Armesto MR. Combination of carvacrol and thymol: antimicrobial activity against Staphylococcus aureus and antioxidant activity. Foodborne Pathog Dis. 2019;16:622-9. https://doi.org/10.1089/fpd.2018.2594

57. Sidiropoulou E, Skoufos I, Marugan-Hernandez V, Giannenas I, Bonos E, Aguiar-Martins $\mathrm{K}$, et al. In vitro anticoccidial study of oregano and garlic essential oils and effects on growth performance, fecal oocyst output, and intestinal microbiota in vivo. Front Vet Sci. 2020;7:420. https://doi.org/10.3389/fvets.2020.00420

58. Samuel KG, Wang J, Yue HY, Wu SG, Zhang HJ, Duan ZY, et al. Effects of dietary gallic acid supplementation on performance, antioxidant status, and jejunum intestinal morphology in broiler chicks. Poult Sci. 2017;96:2768-75. https://doi.org/10.3382/ps/pex091

59. Bai J, Zhang Y, Tang C, Hou Y, Ai X, Chen X, et al. Gallic acid: pharmacological activities and molecular mechanisms involved in inflammation-related diseases. Biomed Pharmacother. 2021;133:110985. https://doi.org/10.1016/j.biopha.2020.110985 